ARTICLE

\title{
Phage therapy as a potential solution in the fight against AMR: obstacles and possible futures
}

\author{
Charlotte Brives (10 ${ }^{1 凶} \&$ Jessica Pourraz ${ }^{2}$
}

\begin{abstract}
Phage therapy, the use of bacteriophage viruses to treat bacterial infections, has existed for more than a hundred years. However, the practice is struggling to develop, despite growing support over the past 15 years from researchers and doctors, who see it as a promising therapy in the context of the rise of antimicrobial resistance (AMR). While the reasons for these developmental difficulties are complex, in this article we wish to address the effects of pharmaceutical regulations on phage therapy. By showing how phages are assimilated to an umpteenth antibiotic in legal texts, but also in certain medical practices, this article proposes to analyze the consequences of such regulatory categorization both for their production and the logistics of administration of proof of their efficacy in randomized controlled trials (RCTs), as well as the underlying concepts of infection and treatment. This paper follows Chandler's work on the concept of antibiotics as infrastructure and its inversion presented by antimicrobial resistance. Phages as living, dynamic, evolving, and specific entities, do not lend themselves easily to current categories, norms, and development models. In this sense, they act as disruptors, revealing the limitations imposed by the existing infrastructure. More precisely here, and to continue Chandler's initial thought process, this paper aims to show that antibiotics also form a kind of epistemological infrastructure, which acts as a powerful inhibitor to the development of phage therapy. In this sense antibiotics prevent the development of solutions to the problem they contribute to create. But the difficulties phage therapy faces, as highlighted in this article, can be interpreted as entry points for thinking of another medicine and imagining other possible futures. This analysis is based on a 3-year fieldwork study (2016-2019) in Europe (France, Belgium, and Switzerland), during which we conducted semi-directed interviews with various phage therapy stakeholders (physicians, researchers, pharmacists, regulators, patients, and patient associations), participatory observation in labs and observations during symposia and workshops on phages and phage therapy.
\end{abstract}

${ }^{1}$ CNRS, Bordeaux, France. ${ }^{2}$ Faculté de Sociologie, Université de Bordeaux, Bordeaux, France. ${ }^{凶}$ email: charlottebrives@gmail.com 


\section{Introduction}

hage therapy, the use of bacteriophage viruses to treat bacterial infections, has existed for more than a hundred years (D'Hérelle, 1931). However, the practice is struggling to develop, despite growing support over the past 15 years from researchers and doctors, who see it as a promising therapy in the context of the rise of antimicrobial resistance (AMR). While the reasons for these developmental difficulties are complex, in this article we wish to address the effects of pharmaceutical regulations on phage therapy. For this we have adopted a theoretical approach from science and technology studies (STS) and philosophy of science. More precisely, we use the material-semiotic method of the actor-network theory, and the principle of generalized symmetry that places humans and non-humans on the same analytical plane (Callon, 1986; Latour, 2004). Our postulate is that we cannot understand the difficulties of phage therapy without taking into account both the socio-political context and the very materiality of phages, their characteristics and specificities.

Indeed, efforts to make phage therapy a viable and widely shared practice must be analyzed within the framework of the AMR problem and the solutions proposed to deal with it (Podolsky, 2018). More broadly, while the need to reduce antibiotic use by modulating individual behaviors is often highlighted (Broom et al., 2015), it is the systemic and institutionalized dimension of antibiotics and their use that must be taken into account to understand how a new practice may or may not emerge.

The development of antibiotics, but above all of their modes of production (Bud, 2009) and of mass-consumption, in both human and animal health (Hinchliffe et al., 2018; Kirchhelle, 2018; Fortané, 2019), have had a profound and lasting impact on both human societies and bacteria, thus reminding us that the latter are not inert matter, but living organisms that act and react to their environment (Landecker, 2016).

In a 2018 article, Chandler proposes to mobilize the notion of "infrastructure" as developed by Bowker and Star (1999), among others, as an analytical and programmatic framework to understand the question of AMR: "Such infrastructure comprises materials, information, ordering. For example, the availability and usability of research instruments and subjects shapes what science is constructed; the supply chain, techniques, and subject handling methods are invented alongside biology's conceptual frame" (Chandler, 2018, p. 9). Chandler shows how "the present awareness of antimicrobial resistance appears to have produced an inversion whereby antimicrobials, and their attendant relations and processes, have come to the fore. This enables analyses of the possibilities, conventions, and constraints that have hitherto been taken for granted as common sense, and the potential for reshaping these into the future" (Chandler, 2018).

This inversion of the infrastructure presented by AMR, and the opportunity it offers to think of another medicine, seems to us to be particularly highlighted by the case of phage therapy. Phages, living and dynamic, evolving and specific entities, do not lend themselves easily to current categories, norms and development models. In this sense, they are disruptors, revealing the limitations imposed by the existing infrastructure. More precisely here, rather than reinvesting the various forms of the antibiotic infrastructure through the prism of phages, something that cannot be achieved in a single article, we want to show that antibiotics also form a kind of epistemological infrastructure, which acts as a powerful inhibitor to the development of phage therapy. In this sense, we can say that antibiotics actually prevent the development of solutions to the problem they contribute to create.

In showing this, we must examine the notion of infrastructure as production means. In particular, we will show how regulation and innovation are linked through production means, and how the materiality of phages, evolving entities, imposes constraints on both the respect of production norms imposed by regulations and the dominant model of drug development based on scalability.

After a brief review of the history of phage therapy and the mode of action of phages, we will describe the regulations in force in Europe, which classify bacteriophage viruses as medicinal products and their use, particularly in the French context.

By showing how phages are assimilated to an umpteenth antibiotic in legal texts, but also in certain medical practices, we will analyze the consequences of such regulatory categorization for their production and for the administration of proof of their efficacy in randomized controlled trials (RCTs), as well as the underlying concepts of infection and treatment.

We will conclude with how some of the difficulties facing phage therapy highlighted in this article can be interpreted as entry points for imagining other possible futures.

This analysis is informed by 3 years of fieldwork (2016-2019). As one of us is a member of various scientific networks on phage research and applications, and has trained in Biological Sciences, Anthropology of Science and Biomedical Sciences, she was able to conduct participatory observations in laboratory contexts. We participated as observers in 10 symposia and workshops on bacteriophages and phage therapy, during which we conducted intensive informal discussions with participants. We also conducted 30 semi-directive and/or open interviews with scientists, physicians, pharmacists, patients, start-up actors and regulatory agency officers. ${ }^{1}$ As anthropologists, we are also part of a Randomized Controlled Trial, the aim of which is to assess the added value of phages for bone infections.

These different implications within the phage therapy field meant one of us could participate to a specialized committee on phage therapy at the French National Agency for the Safety of Medicines and Health Products (ANSM). From a strong interdisciplinary perspective, we also presented our work in workshops on phage therapy and in a Jacques Monod conference on viral evolution, generating added conversations and data about actors' perspectives on the development of phage therapy.

\section{A brief history of phage therapy}

Not all viruses are pathogenic to humans. In fact, there is a category of virus, bacteriophage viruses (or phages), which are hosted by bacteria. The human population will soon reach eight billion, but the number of phages present in ecosystems is estimated at more than $10^{31}$, making them the most represented biological entity on Earth. These creatures, made up of protein or proteolipidic capsides containing fragments of nucleic acids (most often DNA, but also RNA), are present wherever bacteria can be found.

Humans have come to know and recognize them since the beginning of the 20th century. First mentioned in 1915 by Frederick Twort (1915), they owe their therapeutic applications to Félix d'Hérelle, who isolated them in 1917 in the feces of convalescing dysentery patients, while he was stationed at the Pasteur Institute in Paris (D'Hérelle, 1917).

Though the nature of the bacteriophages was a matter of dispute only resolved in the early 1940s with the invention of the electronic microscope, d'Hérelle made immediate use of his discovery to treat patients suffering from bacterial infections and reported great success (Summers, 1993, 2001). During these various studies, d'Hérelle collaborated with George Eliava, who then supervised the creation of a center in Tbilisi in his native Georgia, dedicated to this practice and which was posthumously given his name (Dublanchet, 2017). 
While phage therapy developed rapidly in Europe and the United States, with phages even being produced by several American pharmaceutical companies, it declined from the 1940s onwards, remaining in these regions within a very confidential context only (For an overview of this period, see Fruciano, 2011). However, it has developed significantly in Soviet countries, especially Georgia, where it is still widely practiced, as well as in Poland and Russia (For a detailed account of the adoption and survival of bacteriophage therapy in the USSR, see Myelnikov, 2018).

The reasons for the decline of phage therapy are complex, and deserve the full attention of Science historians. However, several convincing arguments can be put forward at this stage. Firstly, two reviews on phage therapy published in 1934 (Eaton and Stanhope, 1934) and 1941 (Krueger and Scribner, 1941) in the prestigious Journal of the American Medical Association (JAMA), reported difficulties in using phages, as well as efficacy problems. However, on reading these reviews it becomes obvious that there were still controversies about the mode of action of these viruses at the time. During the same period, the development of sulfonamides, powerful antibacterial agents, in Germany in the 1930s, and the massive production and use of antibiotics from the 1940s onwards in the United States, ran in parallel to the almost complete disappearance of phage therapy in the years that followed. This argument is consistent with the continuation of this practice in some countries of the former USSR, as access to antibiotics was limited at that time (Kuchment, 2012; Summers, 2012; Myelnikov, 2018). ${ }^{2}$

Phages, sulfonamides, and antibiotics all seemed to do the same thing: destroy bacteria. Sulfa-drugs, but especially antibiotics, first and foremost penicillin, just seemed to do it better. The second half of the 20th century was thus marked by a drastic reduction in infectious diseases. It made antibiotics (and sulfadrugs) one of the greatest achievements in the history of medicine, and they lastingly influenced the de facto definition of what a treatment should be and how it should work. At the same time, and partly because of that, phage therapy plunged into almost total oblivion, to the point that at the end of the 20th century, the hostility toward the use of phages for therapeutic purposes was widely shared, a feeling mentioned by all the physicians we met during fieldwork.

In parallel with this massive rejection by part of the infectious disease community, several attempts to develop phage-based biotechnologies took place in the late 1990s and early 2000s, whether in human health, animal health, or biocontrol in the agri-food sector (Hausler, 2006; Kuchment, 2012). Indeed, it is in the latter sector that some initiatives have been successful. Since 2007, two anti-Listeria phage cocktails have been approved by the FDA and the Canadian Environmental Protection Agency (EPA). They later also obtained authorization from the European Food Safety Agency (EFSA). In conventional and organic agriculture, phages are also used to protect tomato and pepper crops from the pathogens Xanthomonas pestris and Pseudomonas syringae (Zaczek et al., 2015).

However, the use of phages for therapeutic purposes in human health never completely disappeared during this period. In France and in Belgium, for example, phage therapy has continued to be used occasionally to treat patients in cases of therapeutic failure (Patay et al., 2019). Over the past 15 years, phage therapy has been under development again in laboratories and hospitals. While the results of the first large-scale clinical trial based on a European consortium, Phagoburn, are inconclusive (Jault et al., 2019), ${ }^{3}$ more and more patients are being treated by phages in France and Belgium (Jennes et al., 2017; Ferry, Boucher et al., 2018, Ferry, Leboucher et al., 2018; Djebara et al., 2019). In the United States, the case of Tom Patterson, who was infected in Egypt by a toti-resistant strain of Acinetobacter baumannii, brought back to the United States in a critical condition, and then treated by phages that cured him at University of California San Diego, has given rise to numerous articles and a book which enjoys considerable sales (Strathdee and Patterson, 2019). In England, the case of a cystic fibrosis patient with a disseminated drug-resistant Mycobacterium abscessus infection was published in Nature after the patient was cured by the use of natural and synthetically modified phages (Dedrick et al., 2019). Several trials are underway or will begin in the coming months, the number of scientific publications on the subject has significantly increased, and the various microbiology conferences held in recent years have given increasing attention to potential therapeutic applications of phages.

This redevelopment of phage therapy may owe much to some of its most ardent advocates, but it actually responds above all to a concern that has been growing since the beginning of the 21st century around the appearance of "superbugs". This is because while phages and certain antibiotics do have a biocidal competence, their mode of action is fundamentally different. ${ }^{4}$

\section{On phages' mode of action and potential uses}

While antibiotics are chemical substances, phages are strict parasites of bacteria, biological entities that have complex and co-evolving relationships with them. Phages can be said to be virulent or temperate depending on their development cycles: lytic (destruction of the bacterial cell by the phage) or lysogenic (insertion of the genetic material of the phage into the bacterial DNA, which then gives the bacterium immunity to infection by an identical phage). In the context of therapeutic use, only virulent phages, i.e. phages that can only perform lytic cycles, are therefore relevant.

Figure 1 illustrates the lytic cycle of phages. During the adsorption phase, the phage attaches itself to the bacterial membrane. This step is highly specific; a given phage will generally only be able to attach itself to a given bacterial species, and sometimes to only some strains (genetic variants) of that species. It then injects its genetic material into the bacterium, which will be replicated via bacterial enzymes, which will also synthesize the proteins and lipids needed to form capsides. After assembling the different components to form virions, the bacterium will be lysed, releasing between 50 and 200 new phages, which can attach themselves to new bacteria and start the cycle over again.

In therapeutic use, it is therefore necessary to isolate active phages against the bacteria responsible for the patient's infection, amplify them, and administer them in such a way that they come into contact with the pathogen. In the case of an osteo-articular infection, for example, one of the ways to proceed is to wash the wound with a phage solution before closing it at the end of surgery. Phages, multiplying in contact with the host bacteria, will spread as long as there are cells left to infect. Once the pathogen is eliminated, the phages, which cannot survive without a host, will then be degraded.

The mode of action of lytic phages, which is highly specific, allows for the consideration of the history of infection and the development of a therapeutic approach that takes into account its particularities. Phages could thus make it possible (and already do so on an ad hoc basis) to treat a number of cases considered critical, which are becoming more and more numerous as part of the gradual establishment of AMR. They could also be an alternative to antibiotic use, or used together. Some studies show their synergistic potential and a reduced acquisition of resistance in bacteria (Chaudhry et al., 2017). They could be used to decolonize patients before surgery, or to decolonize carriers of Staphylococcus aureus working with immune-depressed patients (Narasimhaiah, 2013).

The specificity of phages makes it possible to target only the pathogen responsible for the infection to be treated, and thus to 


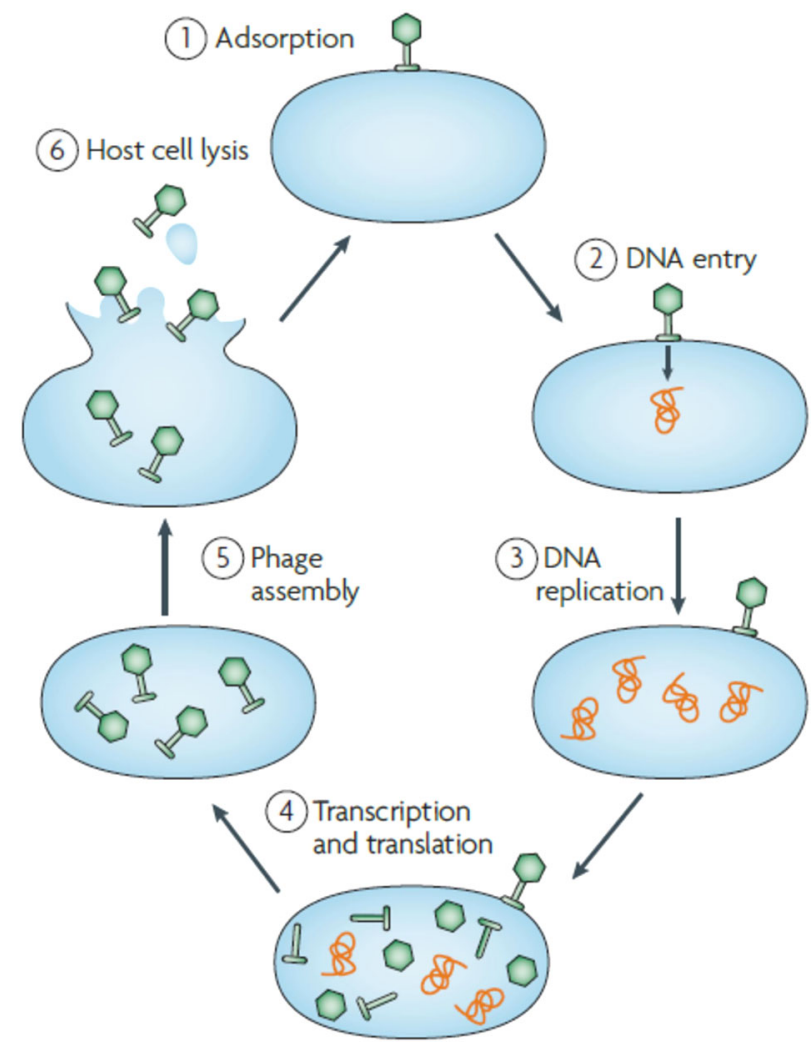

Fig. 1 The phage replication cycle. This figure is not covered by the Creative Commons Attribution 4.0 International License. Reprinted by permission from Springer Nature: Nature Reviews Microbiology,

Bacteriophage Resistance Mechanisms, Simon J. Labrie et al. (2010), all rights reserved.

preserve the commensal or mutualist bacteria that compose the microbiota, whose role in human health we are only just beginning to understand. But this potentiality offered by phages depends in part on the type of approach favored in the development models of the therapy (a point to which we will return more precisely in our conclusion).

In an article published in 2011, following the First International Congress on Viruses of Microbes held from June 21 to 25, 2010 at the Pasteur Institute in Paris, the 19 authors, who are all phage specialists, contrasted two approaches: "prêt-à-porter" and "sur-mesure". The 'prêt-à-porter' approach can be understood as the production of fixed cocktails: several phages (it can be about 10) are put together in order to have at least one that will be effective on the strain carried by the patient to whom the cocktail will be administered. This approach allows for standardized commercial products. "Sur-mesure" describes an approach where patients will only be administered the few phages that are actually active on the strain responsible for their infection. In just a few paragraphs, the authors combine AMR, regulation, microbial evolution, drug market, technical problems, fundamental research, pharmaceutical companies, hospitals, intellectual property, sewage and scientific evidence, to name but a few, all necessary to understand the relevance and wisdom of the opposition between these two approaches. While they argue that the two can coexist, the authors' wish is to see the development of the "sur-mesure" approach, which they believe takes into greater account the particularities of phages and their interactions with bacteria (Fig. 2).

Since the publication of this article, discussions have been initiated at the European level to try to give substance to this second approach, especially since requests from both patients and physicians continue to increase. The Belgian government, in partnership with a research team from the Queen Astrid Military Hospital, has even modified its regulations since 2017 (Pirnay et al., 2018), a point to which we will return below.

Whether in the literature of or in the various interviews conducted over the past 2 years, the issue of regulation appears to be central. Until the early 2000s, the term "bacteriophages" did not appear in any regulatory text. In recent years there has been a desire to regulate practices. However, the way they are captured in the texts leads to a preference for the 'prêt-à-porter' model. In the rest of this article, we will describe the concrete consequences of this regulatory capture for the development of this therapy and its potential role in the fight against AMR.

\section{The regulatory framework: phages as industrial medicinal products}

There is no specific regulation around phages. Since 2011, phages have been considered as a drug in the United States (Fauconnier, 2019) or a medicinal product in the European Union $^{5}$ : a substance or combination of substances that is intended to treat, prevent or diagnose a disease, or to restore, correct or modify physiological functions by exerting a pharmacological, immunological or metabolic action", as defined on the European Medicines Agency (EMA) website. ${ }^{6}$ As mentioned in Volume 1 of Rules Governing Medicinal Products in the EU, "Today the EU legal framework for medicinal products for human use guarantees high standards of quality and safety of medicinal products, while promoting the good functioning of the internal market with measures that encourage innovation and competitiveness." 7

This qualification of phages as a medicinal product for human use was endorsed on June 8, 2015 at an EMA workshop, even though those present at the event who were all working on phage development (doctors, microbiologists, pharmacists, specialists in phage-bacteria interactions), warned that such categorization was inadequate. Following this meeting, they expressed their opposition in a short two-page letter, mentioning two aspects in particular: (i) the need to create a new regulatory framework, which would (ii) counterbalance the lack of public and private investment in phages (Debarbieux et al., 2015).

In order to better understand their position, let us return briefly to the categorization of phages as medicinal products as per the European Directive 2001/83/EC. It applies "to medicinal products for human use intended to be placed on the market in Member States and either prepared industrially or manufactured by a method involving an industrial process" (Fauconnier, 2019, p. 2). For ease of writing, we will refer to them as 'industrial medicinal products' in the following sections. This applies to the member countries of the European Union but also to the United States, since both are members, along with Japan, of the International Conference on Harmonization of Technical Requirements for Registration of Pharmaceuticals for Human Use (ICH) created in 1990. The ICH's objective is to create a global market through the harmonization of regulatory requirements relating to the quality, safety, and efficacy of medicines by implementing the principles of reciprocity and mutual recognition between the three reference regulatory authorities of the United States, Japan, and the European Union. ${ }^{8}$ Therefore, rules and guidelines that apply in Europe also apply in the United-States and more broadly, as they have become international standards.

This has three major consequences: (i) phages must be produced according to good manufacturing practices (GMPs), a set of strict standards and procedures to ensure the quality of the finished product; (ii) phages must demonstrate their efficacy and 


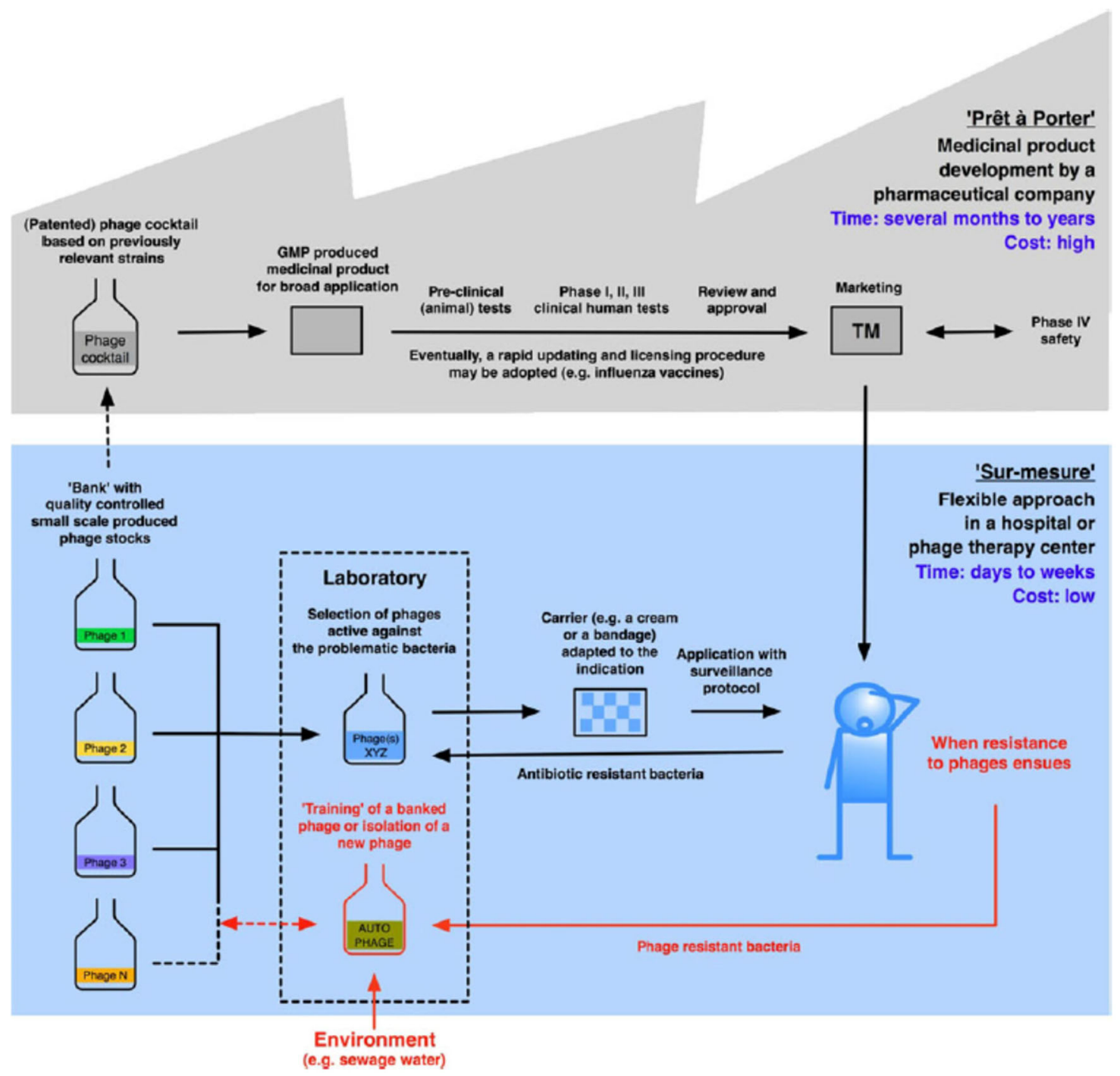

Fig. 2 Phage therapy concepts, 'prêt-à-porter' vs. 'Sur-mesure'. This figure is not covered by the Creative Commons Attribution 4.0 International License. Reprinted by permission from Springer Nature: Pharmaceutical Research, The Phage Therapy Paradigm: Prêt-à-porter or Sur-mesure? Jean-Paul Pirnay et al. (2011), all rights reserved.

safety in RCTs (Phase I, II, III, and IV); (iii) phages must obtain marketing authorization. Research and development on phages is thus placed within the framework of an industrially based drug economy.

This is the case in France, where phages must be prepared industrially by pharmaceutical establishments according to GMPs. ${ }^{9}$ GMPs are part of the quality assurance system put in place by the pharmaceutical industry to ensure the production of medicines in a systematic, standardized, and controlled manner according to the quality standards appropriate to their use, and in compliance with the granting of marketing authorization by the national regulatory authorities (Brhlikova et al., 2007). In France, the marketing authorization is delivered by the French National ANSM after evaluating the dossier submitted by the pharmaceutical industry. It must include the results of clinical trials demonstrating efficacy and elements regarding the benefit/risk ratio. Currently there is no marketing authorization for phages in France, the European Union, or the US.

While they cannot fulfill these different obligations, phages are generally used in the context of Article 37 of the Helsinki Declaration (for a detailed inventory of the different regulations in the European Union countries, see Pirnay et al., 2019).
In the United States, patients can be treated by phages following the emergency investigational new drug (eIND) pathway of the FDA (expanded access program). ${ }^{10}$ In France, the ANSM has opted for an accompaniment of compassionate uses in the form of a Temporary Use Authorization, which normally applies to products under evaluation or about to obtain a marketing authorization. Although the phages available in the country, and in the European Union more generally, do not yet meet these requirements, there are phages still in the prototype stage (produced by research laboratories) which are not manufactured according to GMP standards, that the ANSM regularly supports for several patient treatments, thus demonstrating its commitment to promoting this therapy. ${ }^{11}$

From the cases that we have observed or documented or that have been reported to us during interviews, a patient's treatment plan can be summarized as follows: after discussion and validation with the ANSM and a committee of experts on the appropriateness of the use of phages in the treated infection, the infectiologist or physician in charge of the patient takes a bacterial sample, isolates the pathogenic strain and sends it to one of the laboratories likely to have one or more active phages. The latter performs a phagogram, i.e. s/he tests the activity of the different 
phages available to her/him on the bacterial strain. If one or more phages are active, they will then be produced and purified and sent to the pharmacist and physician for administration.

It appears that the main limiting factor today is the number of phages available to doctors, which might seem counter-intuitive given that phages are the most abundant biological entity on Earth. The high specificity of phages for bacteria implies the need to have a wide enough diversity of phages available to be able to find one or more that are likely to be effective in treating the infection of a given patient. When a bacterial strain is sent to laboratories likely to have active phages, the phagogram is most often negative. One of the doctors we met sent a bacterial strain to seven different laboratories all over Europe to find an active phage. These were research laboratories, rather than pharmaceutical companies or start-ups. Another frequent occurrence is that in the absence of active phages within available collections, research laboratories engage in phage hunting, searching for new phages in the rich waters of the surroundings (waste water, sewers, treatment plants), before producing and sending them. This scheme is beset with problems, which manifest themselves as many scientific and technical steps and challenges in the development of phage therapy. However, some are more significant than others, and are directly related to the categorization of phages as industrial medicinal products.

The practices described above are only tolerated. While the ANSM, for example, supports doctors who want to treat patients with phages produced by research laboratories (phages that obviously meet strict specifications in order to prevent any toxicity), the fact remains that, in line with European regulations that make phages medicinal products, the agency favors phages produced according to GMP standards, i.e. industrial phages.

Here, the materiality of phages and their coevolutionary capacities with bacteria come into play. Phages are dynamic entities that evolve very quickly. One of the problems faced by phage producers is then to ensure the stability of their product, a difficult task as phages are produced using bacteria. Consequently, producers must not only isolate, characterize, and purify phages, but they also have to stabilize them to prevent them from mutating. Another problem faced by producers is cross-contamination, since phages are able to interact with non-targeted bacteria. This is a well-known problem in dairy industry, where phages are considered a nuisance, as they can destroy the bacteria needed for fermentation processes. This therefore implies the construction of dedicated production units, including clean rooms, where the particle concentration is controlled in order to limit the risks of contamination, as well as the required temperature, humidity, and pressure levels. These kinds of facilities are very costly.

In addition, it should be noted that producers face ownership problems. Currently, as a Belgian physician told us, the only ownership protection available is in the form of 'gentleman's agreements'. This is untenable for start-up actors we've met, who are actively searching for solutions to protect their work. Indeed, unlike chemical molecules that can be quite easily patented, phages are natural entities, and are currently not patentable (whether in North America or Europe). Different strategies are evoked in interviews or in published papers: processes (of production, of purification) could be patented; or 'trade secrets' model could be followed, where, like for the Coca-Cola recipe, a company would not disclose their know-how, in order for some start-ups to maintain their advantage over potential competitors (Todd, 2019). This contributes to the difficulties for start-ups to find and keep investors, and can also explain, along with Big Pharma disengagement from the field of anti-infective drugs, why pharmaceutical firms are not committed to the development of phage therapy.
Surviving start-ups established in the 2000s therefore generally work on only a few specific phages of a few bacteria, most often Staphylococcus aureus or Pseudomonas aeruginosa, responsible for the most commonly encountered antibiotic-resistant infections, but also more rarely and more recently Escherichia coli.

The categorization of phages as an industrial medicinal product thus leads to a discrepancy between the need to have large collections of phages available (even if not all the different interlocutors hold the same view on the number of phages needed or the degree of specificity-questions that we do not address here because they are not necessary at this stage), and production standards, which are designed within the framework of the commodification of health products, and which make it very difficult (in terms of financial, human, and technical means) to obtain a large number of phages manufactured in compliance with GMPs.

This is one of the reasons why the Belgian Government, under the impetus of a team of researchers from the Queen Astrid Military Hospital in Brussels, decided in 2017 to no longer consider phages as industrial medicinal products but as Active Product Ingredients in magistral preparations (APIs). This move has allowed the Belgian hospital to manufacture phages for treatment. However, there are still points that need to be clarified, as there is no clear consensus on the requirements and standards for API production. For some people we met, APIs must meet the same standards as medicinal products. This once again reveals the difficulties encountered by all actors around the understanding of the regulatory texts and the possibility of including phage therapy in them.

From this point of view, classification as an API does not solve the issues and difficulties of production. To this we must add that although this shift may facilitate access to therapy for individual patients, it does not, however, allow the realization of RCTs, which are conditioned on the use of phages produced according to GMP standards. Yet RCTs are absolutely necessary for the development of phage therapy, even if, as we will see, the administration logistics of the evidence of phage efficacy via RCTs is problematic to say the least.

\section{Categorizing anti-infectives: phages as an umpteenth antibiotic}

In the problems frequently raised by the various actors involved, whether doctors, researchers, pharmacists, or regulators, the difficulty of producing evidence of phage efficacy occupies an important place. Although everyone may agree on their necessity to demonstrate the safety and efficacy of phages, RCTs, the gold standard of Evidence-Based Medicine, are considered as another obstacle to the development of phage therapy. Indeed, at this time, the only conclusive trial on phage therapy relates to the treatment of chronic otitis (Wright et al., 2009). The argument most frequently used in interviews, but also in scientific articles, concerns the strong specificity of phages.

While the failure of the first major trial in Europe, Phagoburn, highlighted some technical problems (Jault et al., 2019), several articles published by proponents of phage therapy in Europe during the last few years focus on two main elements: (i) the inadequacy of clinical trials to demonstrate the efficacy of phages because of their specificity and therefore the personalized nature of the treatment (Pirnay et al., 2019); and (ii) the major difference between what is evaluated in trials and what occurs in real life (Patay et al., 2019).

These two types of arguments, albeit crucial, are not specific to phages. Out of all the interviews conducted, in this section, we mainly focus on comments from two physicians, both of whom are actively working on the development of clinical trials in 
France. Their roles are which is representative of the positions held by all of the interviewees: a doctor who has spent her entire career in Big Pharma, who was in charge of an anti-infective drugs department, and is now working on phage development in a start-up; and a French physician, head of an infectious diseases department in a public hospital which regularly uses phages.

Thus, in an interview about the pitfalls of clinical trials, the doctor working in the start-up dismissed specificity as a valid reason to explain the difficulties in the development of this therapy:

"I am however less concerned about specificity. Antibiotics and bacteria may not evolve together and they're not two living entities (...), but antibiotics also target very specific bacteria. So I'm not hugely convinced about the idea of specificity." (June 2019).

Indeed, personalized therapies are evaluated by RCTs on a daily basis. In the field of infectious diseases more specifically, the antibiotics developed over the past 20 years are themselves very specific, which has not prevented them from proving their efficacy. Regarding the difference between clinical trials and real life, the existing literature clearly demonstrates that this problem is not specific to phages, but concerns all trials, except phase IV trials, which are set up precisely to close this gap (Brives et al., 2016; Adams, 2016; Brives, 2018). This is not to say that these two problems are not important, only that, as they arise for all treatments, they alone cannot explain the obstacles to the development of phage therapy. While the specificity of phages is central in the understanding of the barriers imposed by current regulations, particularly regarding production issues, it is only one problem among many which help to illustrate the difficulties faced by physicians and researchers in assessing the efficacy of phages. So, what makes it so difficult to produce evidence in the case of phage therapy?

Phages as an umpteenth antibiotic. It was through discussion with physicians, epidemiologists, and funders, and analysis of the design of clinical trials, both those already carried out and the one we are currently involved in, that another hypothesis emerged. Indeed, in most of the interviews conducted on evidentiary practices with physicians, epidemiologists, and regulators, we found that phages were considered as another type of antibiotic. Thus, as mentioned by the French physician working in the public hospital:

"Phages are one solution among others, because there are lots of interesting ideas coming out. There are new antibiofilm antibiotics, antibodies coupled with antibiotics which deliver the antibiotic to the inside of cells, and there are specific anti-infective gels which can carry antibiotics."

(April 2019).

This assimilation is even more clearly reflected in the comments of the physician working in the start-up:

"I see it more in terms of a toolbox: what tools do I have as an infectiologist when I'm faced with an infection, and what do I use to treat that infection. Phage therapy is one of those tools, but I see it as pretty much the umpteenth antibiotic (...) That's how I see it. It's an additional tool you can use to treat the patient."

(June 2019).

This interpretation has recently been reinforced by the latest guideline concerning the Evaluation of medicinal products indicated for treatment of bacterial infections (European Medicines Agency, 2019), whose aim is to "facilitate clinical development programs for new antibacterial agents (...) to ensure that each clinical trial conducted can be designed to meet the requirements of multiple regulatory agencies" (European Medicines Agency, 2019, p. 4). While previous versions of this guideline never mentioned phages, this one states that principles covered in this guideline are also applicable to their development (European Medicines Agency, 2019, p. 5), a point emphasized by the physician later in the same interview:

"It means that the pathway might not be the same, but in any case we must stick as closely as possible to the existing guidelines for antibiotics."

\section{(June 2019).}

These new guidelines imply that the efficacy of phages must be proven on the same basis as that of any antibiotic. The problem is that due to ethical standards, which state that patients must always be given the best available treatment, phages are systematically used with antibiotics. This has a major consequence for the design of RCTs. The public hospital infectiologist says:

"For incontestable scientific proof, we'd need to conduct a therapeutic trial; a therapeutic trial with hundreds of patients who are randomly selected for surgery + antibiotic treatment versus, and this is where it get more complicated, other patients with the same infection who receive surgery + antibiotics + phages."

\section{(April 2019).}

And indeed, the design of the different trials, conducted, about to start, or under development, systematically contrasts a control arm using antibiotics and an intervention arm using phages + antibiotics.

What is tested is therefore not one anti-infective against another, but only the increase in efficacy associated with the addition of phages to antibiotics. This poses two challenges: (i) due to the specificity of phages towards a given bacterium, all recruited patients must be infected with the same bacterium, or even with only certain strains of this bacterium (those sensitive to phages); (ii) since antibiotics are still quite effective, except in the case of toti-resistant bacteria, the number of patients that would need to be included to statistically show a significant increase in efficacy is colossal.

We are faced here with a problem: if AMR is indeed increasing, and is certainly already a problem, it is above all a problem in the making; for the time being antibiotics retain a large part of their efficacy, which makes it extremely difficult, time-consuming and costly to demonstrate the efficacy of phages according to current EBM standards.

Eradication or containment, or how to use phages and antibiotics. Another problem with the assimilation of phages to antibiotics in RCTs concerns the efficacy criterion chosen. With regard to the protocols and discussions conducted with clinical trial investigators, the most robust efficacy criterion for an antiinfective drug is the eradication of the pathogenic bacterium, as the start-up doctor, who is currently working specifically on the criteria issue pointed out:

"A robust efficacy criterion for an anti-infectious product is usually to show that the infection no longer exists, that the bacteria is no longer present."

(February 2019). 
However, the current use of phages in therapy makes this criterion particularly difficult to document. For example, two trials are about to begin, one on prosthetic Staphylococcus aureus infections and the other on foot ulcer infections in diabetic patients. In both cases, once the wounds have healed, it becomes very difficult to document the eradication of the bacterium. If this is not an issue in itself for these phase II trials, which are not intended to prove the efficacy of phages but their absence of toxicity, it is a concern for phase III trials, as several physicians have pointed out in the various interviews conducted.

Eradication as a criterion of efficacy also raises questions about the relevance of definitions of cure in the context of infectious diseases. While eradication is perfectly justified in some cases, particularly in the treatment of acute infections, several doctors are more measured for chronic infections, for which phages would be particularly suitable. Thus, an intensive care physician at a major Parisian hospital, who is also doing a Biological Science $\mathrm{Ph}$.D. thesis on phages, explained to me that in the case of chronic infections, it was not so much the eradication of the bacterium, but rather the restoration of a better functional status of the patient that was targeted:

"I think we'll continue to use antibiotics for probabilistic, empirical circumstances. For example, when you come to hospital with pyelonephritis, there's no time, we don't know who you are, and we treat you with medicine because it's an emergency. But I believe phages have a place in the treatment of more chronic infections. I think it's a problem that antibiotics are constantly trying to eradicate things: niches that are actually favorable to strains. And the problem is if you eradicate something that wasn't actually all that bad, you don't know what it might be replaced with."

\section{(November 2018).}

This argument was also mentioned by a cystic fibrosis specialist who reminded us during a workshop that his aim was not to eradicate a multi-resistant lung infection, but rather to maintain it at a tolerable level for his patient. ${ }^{12}$ This approach was also favored by an infectiologist working on complex osteo-articular infections, who recalled during an interview the multiple definitions attributed to healing, and the choices that were made according to the patient. If the microbiological definition of healing is indeed the eradication of infection, which may for example require the amputation of a limb, the orthopedic definition will be the preservation of that limb by maintaining an infection at a threshold acceptable to the patient. ${ }^{13}$

These statements, which reflect an ecological and holistic vision of the disease, made up of interspecific population dynamics, do not reject eradicationism. They only make it a possibility of action among others in achieving healing according to the patient's biographical context. Thus, the distinction between acute and chronic infection is fundamental, as is the distinction made by the intensive care physician between phages and antibiotics. Two substances, two different entities, which, because of their differences, will not be used to achieve the same objectives.

By highlighting the range of relationships we have with microbes, by showing that infection can be tolerated if it allows the maintenance of a good functional status for the patient or if it prevents a more virulent and difficult-to-treat pathogen from occupying the environment, by pointing out that mediating entities do not have the same agencies, these researchers reveal a clear discrepancy between what happens in infection management practices (with or without phages, antibiotics for example being able to act as mediators of pathogen virulence as well) and guidelines, recommendations, and regulations on anti-infective products.

Although these divergences make it very difficult, timeconsuming and costly to prove the efficacy of phages via clinical trials designed according to current guidelines and regulations, it is not impossible. But according to the various actors we met, it will demand adjustments and negotiations, a point highlighted by the start-up doctor's comments after one and a half hours of discussion on efficacy and cure criteria:

"I'm the first to say that the dogma of antibiotics has a hold over me. There are guidelines and we must follow them as closely as possible, or it won't be accepted. (...)Proof of efficacy will always be required. If today's blueprint is no longer valid, what blueprint do we follow? What is acceptable? I don't have the answer and I can't find it alone (...). Perhaps we need to completely reinvent history, the whole history of proof of efficacy. And we're not going to do it alone."

(June 2019).

In all the interviews we conducted, all the actors (regulators, doctors, pharmacists, researchers, investors) agreed on the need to produce reliable data via RCTs. While there is a consensus on this point, potential solutions have yet to be found. Phages are biotherapies, in the same way as maggots, larvae, helminths (Grassberger et al., 2013), and more recently the fecal microbiota transplant (FMT) to treat Clostridium difficile infections. As such, it might be interesting to look at how these therapies have been evaluated in the framework of RCTs. However, if in these different cases, living dynamic entities are used in human therapy, an additional constraint is placed on the therapy in question. As we have already mentioned, phages are not only highly specific, which makes them similar to personalized medicine (for which specific designs exist, such as the n-of-1 trial, designed for one patient), but also very unstable due to their evolvability. This is not to say that RCT is totally unsuited to this therapy, but rather that the problems it faces, which are both regulatory and epistemological, can only be resolved through collegial and highly interdisciplinary discussions.

\section{Conclusion/discussion}

According to the various stakeholders met, and in view of the increasing number of documented cases available, phage therapy appears to be a promising alternative in the treatment of certain bacterial infections, multi-resistant or not. Due to the lack of data from RCTs, phages are currently only used in complex cases for patients in therapeutic failure, and are always accompanied by antibiotic treatment. However, the possibilities of application are multiple, and it is entirely conceivable that they could in some cases be used instead of antibiotics. Thus, they potentially have the power to control some existing superbugs, while limiting the emergence of new ones, by limiting the use of antibiotics. The potential applications go well beyond human health, being applicable also to biocontrol, animal health and the environment (Mahony et al., 2011; Chan and Abedon, 2015; Buttimer et al., 2017; Fernandez et al., 2018).

But phages, dynamic and evolutionary entities, are, as we have shown, framed, classified, categorized, as chemical molecules. In furthering Chandler's line of thought, we therefore wished to show that we can think of antibiotics as an epistemological infrastructure that constitute an obstacle to the development of phage therapy, imposing constraints, and conceptions of treatment and cure, eradicationism being the baseline. Once again, 
there is no question of denying the importance of RCTs, only of showing the issues and assumptions around their design.

However, it seems important to us to conclude on the different conceptions of life mobilized in biomedicine and, beyond that, in the choices of development models and public health policies.

In an article on AMR, Hannah Landecker highlights how the development, followed by the production and mass consumption of antibiotics, has contributed to changing the very biology of bacteria. "The bacteria of today are not the bacteria of yesterday, whether that change is registered culturally, genetically, physiologically, ecologically or medically" (Landecker, 2016, p. 3). In the history of antibiotic treatment, what has not been sufficiently taken into account, despite early warnings from scientists and doctors (Gradmann, 2017), are the formidable adaptive capacities of bacteria, and of living organisms in general. What has been denied is the ability of the living to act and react. Phages, through their long co-evolutionary history with bacteria, are a valuable resource. Therefore, their assimilation to other ranges of antiinfectives, which are chemical molecules and not biological entities, results from a reification of living organisms, which considerably reduces the consideration of their agency. This could then be problematic, with regards to both the modalities of their use and the consequences of these.

By assimilating phages to industrial medicinal products, the current regulations thus impose a de facto commodification of living organisms, and a form of forced scalability, to which, as we have seen, phages are difficult to mold. But the difficulties raised by this commodification are not insurmountable. With time, determination and financial resources, start-ups and/or pharmaceutical companies will eventually market 'prêt-à-porter' cocktails that will aim to eradicate several different bacteria. And then the assimilation of phages to antibiotics will take place, giving physicians a 'product' that will only partially correspond to the expectations and practices of the infectiologists and doctors we met, who maintain a rather more ecological and dynamic conception of infection. ${ }^{14}$

We can identify two potential problems here. Firstly, nobody today is able to predict the effect of mass use of phage cocktails, all the more so if their use in animal health or biocontrol were to become more widespread. The data accumulated over the last 20 years or so on microbiotes, and well before that on microbial ecosystems, lead to a certain humility concerning the potential applications of this new knowledge offered by Science. We no longer have the luxury today of being able to disconnect the use of phages in human and non-human contexts.

Secondly, the price of phage treatment is likely to be very high. The abandonment by Big Pharma of the development of antibiotics for economic and financial reasons in favor of much more profitable drugs to treat chronic conditions (Green, 2007) has led to the arrival of a large number of start-ups and small companies. This situation is similar for the production of phages, which depends on the commitment of start-ups and the goodwill of shareholders and investors. In the case of phage therapy, start-ups could be supported by not-for-profit $\mathrm{R} \& \mathrm{D}$ organizations, such as CARB-X in the United States or GARDP in Switzerland, created recently for the development of new antibacterial treatments. However, as far as we know, these organizations have so far favored chemicals. This development model, based on start-ups, implies access will be to a very limited part of the world population, when we know that AMR problems will primarily impact the Global South.

Denying the specificities and temporalities of microorganisms, and commodifying them poses significant risks. Other models, which could produce phages at a lower cost, and enable a case-bycase approach are possible. These models can take into account the specificities of phages and their relationship to bacteria, and are not exclusively based on eradication; if we remain cautious about the appearance of a probiotic turn (Lorimer, 2017), phages, by their very nature, their plasticity and their omnipresence, constitute a wonderful case study for rethinking our relationships with non-human living beings, and documenting and analyzing the way we construct these relationships, as well as the material consequences of these enactments. These models can also take into account the ever-increasing inequalities in access to care, in a context of austerity that affects both the Global South and the countries of the North; because economic actors face problems of privative appropriation, and because phages are not entirely scalable, in the sense developed by Tsing (2015), it is possible to envision an exit from a capitalist model of production.

It is now a question of taking note of these differences, and therefore slowing down, to follow Isabelle Stengers' suggestion (2018) to take the time to design new ways of interacting with microbes, and new paths to think of medicine and care. In this sense, the various bottlenecks identified in this article based on the data presented can be interpreted as many entry points, as many opportunities, to imagine possible futures, "material futures [that are not] produced by what we thought we knew" (Landecker, 2016, p. 19).

\section{Data availability}

The original data generated during and/or analyzed during the current study are not publicly available as individual privacy could be compromised but are available from the corresponding author on reasonable request.

Received: 19 December 2019; Accepted: 22 April 2020; Published online: 19 May 2020

\section{Notes}

1 Interviews lasted between 1.5 and $3 \mathrm{~h}$. They took place face-to-face and were recorded, transcribed, and anonymized.

2 We do not elaborate here on the considerable importance of bacteriophages for the development of molecular biology, since exchanges between fundamental research and therapeutic applications have been, in view of current research, almost nonexistent. (For a history of these viruses and their role in the production of scientific knowledge, see Kay 1993, Morange 1998.) We also leave to one side phage-typing, a method used for detecting single strains of bacteria, and a powerful tool of 20thcentury epidemiology (Kirchhelle, 2019).

3 For complex reasons related less to the effectiveness of phages than to the actual design of the clinical trial protocol and the choice of infections to be treated.

4 Not all antibiotics are biocidal. Some act by preventing bacterial multiplication.

5 Directive 2001/83/EC of the European Parliament and the Council on the Community code relating to medicinal products for human use.

$6 \mathrm{https} / /$ www.ema.europa.eu/en/glossary/medicinal-product (consulted on August 20, 2019).

7 https://ec.europa.eu/health/human-use/legal-framework_en (consulted on August 20, 2019).

8 However, no association of generic manufacturers and no regulatory authority from "Southern" countries participate in ICH. The WHO has only one observer seat but no voting rights (Hauray, 2006).

9 As per Article L. 511-1 of the French Public Health Code.

10 https://www.fda.gov/drugs/investigational-new-drug-ind-application/emergencyinvestigational-new-drug-eind-applications-antiviral-products (accessed on 4 March 2020).

11 In the US, some patients are treated with phages following the emergency investigational new drugs (eNID) pathway of the FDA (for more details see Fauconnier, 2019).

12 Personal communication, 21 March 2019.

13 interview conducted on 26 April 2019

14 This conception is not knew: an "ecological vision in biomedical science" can be found in the work of scientists like Theobald Smith, F. MacFarlane Burnett, René Dubos, or Frank Fenner, which remained of minimal interest until the 1980s, when it was used to explain disease emergence and antibiotic resistance (Anderson, 2004). 


\section{References}

Adams V (2016) Metrics. What counts in global health. Duke University Press, Durham

Anderson W (2004) Natural histories of infectious disease: ecological vision in twentieth-century biomedical science. Osiris 19:39-61

Bowker GC, Star SL (1999) Sorting things out, classification and its consequences. The MIT Press, Cambridge

Brhlikova P, Harper I, Pollock A (2007) Good manufacturing practices in the pharmaceutical industry, Working Paper 3. Workshop "Tracing Pharmaceuticals in South Asia”, University of Edinburgh, p. 35

Brives C (2018) From fighting against to becoming with, viruses as companion species. In: Vigne JD, Stépanoff C (eds) Hybrid communities: biosocial approaches to domestication and other trans-species relationships. Routledge, London, pp. 115-126

Brives C, Le Marcis F, Sanabria S (2016) What's in a context? Tenses and tensions in evidence-based medicine. Med Anthropol 35(5):369-376

Broom A, Broom J, Kirby E, Adams J (2015) The social dynamics of antibiotic use in an Australian hospital. J Sociol 52(4):824-839. https://doi.org/10.1177/ 1440783315594486

Bud R (2009) Penicillin: triumph and tragedy. Oxford University Press, Oxford

Buttimer C, McAuliffe O, Ross RP, Hil C, O’Mahony J, Coffey A (2017) Bacteriophages and bacterial plant diseases. Front Microbiol. https://doi.org/ 10.3389/fmicb.2017.00034

Callon M (1986) Some elements of a sociology of translation: domestication of the scallops and the fishermen of St. Brieuc Bay. In: Law J (ed) Power, action and belief: a new sociology of knowledge. Routledge \& Kegan Paul, London, pp. 196-223

Chan BK, Abedon ST (2015) Bacteriophages and their enzymes in biofilm control. Curr Pharm Des 21:85-99

Chandler C (2018) Current accounts of antimicrobial resistance: stabilization, individualization and antibiotics as infrastructure. Palgrave Commun https:// doi.org/10.1057/s41599-019-0263-4

Chaudhry WN, Concepcion-Acevedo J, Park T, Andleed S, Bull JJ, Levin BR (2017) Synergy and order effects of antibiotics and phages in killing Pseudomonas aeruginosa biofilms. PLoS ONE 12(1):e0168615. https://doi.org/10.1371/ journal.pone. 0168615

Debarbieux L et al. (2015) A bacteriophage journey at the European Medicines Agency. FEMS Microbiol Lett 363:fnv225. https://doi.org/10.1093/femsle/ fnv225

Dedrick RM, Guerrero-Bustamante CA, Garlena RA et al. (2019) Engineered bacteriophages for treatment of a patient with a disseminated drug-resistant Mycobacterium abscessus. Nat Med 25:730-733. https://doi.org/10.1038/ s41591-019-0437-z

Djebara S, Maussen C, De Vos D, Merabishvili M, Damanet B, Pang KW, De Leenheer P, Srachonaru I, Soentjens P, Pirnay JP (2019) Processing phage therapy requests in a Brussels military hospital: lessons identified. Viruses 11:265

Dublanchet A (2017) Autobiographie de Félix d'Hérelle. Editions Médicales Internationales

Eaton MD, Stanhope BJ (1934) Bacteriophage therapy. JAMA 103:1769-76

European Medicines Agency (2019) Guideline on the evaluation of medicinal products indicated for treatment of bacterial infections, Rev. 3, Draft. European Medicines Agency

Fauconnier A (2019) Phage therapy regulation: from night to dawn. Viruses 11:352. https://doi.org/10.3390/v11040352

Fernandez L, Gutierrez D, Rodriguez A, Garcia P (2018) Application of bacteriophages in the Agro-Food Sector: a long way toward approval. Front Cell Infect Microbiol https://doi.org/10.3389/fcimb.2018.00296

Ferry T, Boucher F, Fèvre C, Perpoint T, Chateau J, Petitjean C, Josse J et al. (2018) Innovations for the treatment of a complex bone and joint infection due to XDR Pseudomonas aeruginosa including local application of a selected cocktail of bacteriophages. J Antimicrob Chemother 73(10):2901-2903

Ferry T, Leboucher G, Fèvre C, Herry Y, Conrad A et al. (2018) Salvage debridment, antibiotics and implant retention ('DAIR') with a local injection of a selected cocktail of bacteriophages: is it an option for an elderly patient with relapsing Staphyloccus aureus prosthetic-joint infection? Open Forum Infect Dis 5(11):ofy 269

Fortané N (2019) Veterinarian 'responsibility': conflicts of definition and appropriation surrounding the public problem of antimicrobial resistance in France. Palgrave Commun 5:67. https://doi.org/10.1057/s41599-019-0273-2

Fruciano E (2011) La Phagothérapie, émergence d'une idée controversée et logique d'un échec (1917-1949). Thèse de Doctorat en Histoire et Civilisation. EHESS, Paris

Gradmann C (2017) From lighthouse to hothouse: hospital hygiene, antibiotics and the evolution of infectious disease, 1950-1990. Hist Philos Life Sci 40(1):8

Grassberger M et al. (2013) Biotherapy - History, principles and practice. Springer Green JA (2007) Prescribing by numbers: drugs and the definition of disease. Johns Hopkins University Press, Baltimore
Hauray B (2006) L'Europe du médicament. Politique, expertise, intérêts privés Presse Sciences Po, Paris

Hausler T (2006) Viruses vs. Superbugs? A solution to the antibiotic crisis? Macmillan, New York

D’Hérelle F (1917) Sur un microbe invisible antagoniste des bacilles dysentériques. C R Acad Sci 165(11):373-375

D’Hérelle F (1931) Bacteriophage as a treatment in acute medical and surgical infections. Bull N-Y Acad Med 7(5):329-348

Hinchliffe S, Butcher A, Rahman MM (2018) The AMR problem: demanding economies, biological margins, and co-producing alternative strategies. Palgrave Commun 4:142. https://doi.org/10.1057/s41599-018-0195-4

Jault P, Leclerc T, Jennes S, Pirnay JP, Que YA, Resch G, Rousseau AF, Ravat F, Carsin H, Le Floch R, Schaal JV, Soler C, Fèvre C, Arnaud I, Bretaudeau L, Gabard J (2019) Efficacy and toletaribility of a cocktail of bacteriophages to treat burn wounds infected by Pseudomonas aeruginosa (PhagoBurn): a randomised, congrolled, double-blind phase 1/2 trial. Lancet Infect Dis 19 (1):35-45. https://doi.org/10.1016/S1473-3099(18)30482-1

Jennes S et al. (2017) Use of bacteriophages in the treatment of colistin-onlysensitive Pseudomonas aeruginosa septicaemia in a patient with acute kidney injury-a case report. Critical Care 21(129). https://doi.org/10.1186/s13054017-1709-y

Kay L (1993) The molecular vision of life. Oxford University Press, Oxford

Kirchhelle C (2018) Pharming animals, a global history of antibiotics in food production (1935-2017). Palgrave Commun 4(96). https://doi.org/10.1057/ s41599-018-0152-2

Kirchhelle C (2019) The forgotten typers: the rise and fall of Weimar bacteriophage-typing (1921-1935). Notes Rec https://doi.org/10.1098/ rsnr.2019.0020

Krueger AP, Scribner JE (1941) The bacteriophage. JAMA 116(2160-7):2269-2277. https://doi.org/10.1001/jama.1941.62820190016010

Kuchment A (2012) The forgotten cure, the past and future of phage therapy. Copernicus Books, New York

Landecker H (2016) Antibiotic resistance and the biology of history. Body Soc 22 (4):19-52. https://doi.org/10.1177/1357034X14561341

Latour B (2004) Politics of nature. How to bring the sciences into democraty. Harvard University Press

Lorimer J (2017) Probiotic environmentalities: rewilding with wolves and worms. Theory, Cult Soc 34(4):27-48. https://doi.org/10.1177/0263276417 695866

Mahony J, McAuliffe O, Ross RP, van Sinderen D (2011) Bacteriophages as biocontrol agents of food pathogens. Curr Opin Biotechnol 22:157-163

Morange M (1998) A history of molecular biology. Harvard University Press, Cambridge

Myelnikov D (2018) An alternative cure: the adoption and survival of bacteriophage therapy in the USSR, 1922-1955. J Hist Med Allied Sci https://doi. org/10.1093/jhmas/jry024

Narasimhaiah NH (2013) Therapeutic potential of staphylococcal bacteriophages for nasal decolonization of Staphylococcus aureus in Mice. Adv Microbiol 3 (1):52-60

Patay O, McCallin S, Mazure H, Liddle M, Smithyman A, Dublanchet A (2019) Clinical indications and compassionate use of phage therapy: personal experience and literature review with a focus on osteoarticular infections. Viruses 11:18

Pirnay JP, De Vos D, Verbeken G et al. (2011) The phage therapy paradigm: prêtà-porter ou sur-mesure? Pharm Res 28:934-937

Pirnay JP, Verbeken G, Ceyssens PJ, Huys I, De Vos D, Ameloot C, Fauconnier A (2018) The magistral phage. Viruses 10(64). https://doi.org/10.3390/v10020064

Pirnay JP, De Vos D, Verbeen G (2019) Clinical applications of bacteriophages in Europe. Microbiol Aust. http://microbiology.publish.csiro.au/paper/MA19010. htm

Podolsky SH (2018) The evolving response to antibiotic resistance (1945-2018). Palgrave Commun 4(124):1-8

Stengers S (2018) Another science is possible, a manifesto for slow science. Polity Press, Cambridge

Strathdee S, Patterson T (2019) The perfect predator. Hachette Books

Summers W (1993) Cholera and Plague in India, the bacteriophage inquiry of 1927-1936. J Hist Med Allied Sci 48:275-301

Summers W (2001) On the origins of the science in Arrowsmith: Paul de Kruif, Félix d'Hérelle and Phage. J Hist Med Allied Sci 46:315-332

Summers W (2012) The strange history of phage therapy. Bacteriophage 2 (2):130-133

Todd K (2019) The promising viral threat to bacterial resistance: the uncertain patentability of phage therapeutics and the necessity of alternative incentives. Duke Law J Duke Law J 68:767-805

Tsing A (2015) The mushroom at the end of the world. On the possibility of life in capitalist ruins. Princeton University Press, Princeton

Twort FW (1915) An investigation on the nature of ultra-microscopic viruses. Lancet 10:101 
Wright A, Hawkins CH, Angaard EE, Harper DR (2009) A controlled clinical trial of a therapeutic bacteriophage preparation in chronic otitis due to antibioticresistant Pseudomonas aeruginosa; a preliminary report of efficacy. Clin Otolaryngol 34(4):349-57. https://doi.org/10.1111/j.1749-4486.2009.01973.x

Zaczek M, Weber-Dabrowska B, Gorski A (2015) Phages in the global fruit and vegetable industry. J Appl Microbiol 118(3):537-556

\section{Acknowledgements}

We are grateful to everyone who agreed to meet and participate in our survey. We thank all the members of the different scientific networks on phage therapy for their reflections and for the enriching discussions that helped in the writing of this paper. All interpretations and inaccuracies remain the responsability of the authors. This work was funded in part by the support of the Agence Nationale de la Recherche (ANR) [Grant number ANR-18-CE36-0001] and the New-Aquitaine region [Grant number 20181R40218].

\section{Competing interests}

The authors declare no competing interests.

\section{Additional information}

Correspondence and requests for materials should be addressed to C.B.
Reprints and permission information is available at http://www.nature.com/reprint

Publisher's note Springer Nature remains neutral with regard to jurisdictional claims in published maps and institutional affiliations.

cC (i) Open Access This article is licensed under a Creative Commons Attribution 4.0 International License, which permits use, sharing, adaptation, distribution and reproduction in any medium or format, as long as you give appropriate credit to the original author(s) and the source, provide a link to the Creative Commons license, and indicate if changes were made. The images or other third party material in this article are included in the article's Creative Commons license, unless indicated otherwise in a credit line to the material. If material is not included in the article's Creative Commons license and your intended use is not permitted by statutory regulation or exceeds the permitted use, you will need to obtain permission directly from the copyright holder. To view a copy of this license, visit http://creativecommons.org/ licenses/by/4.0/.

(c) The Author(s) 2020 